\title{
Breaking Barriers: Using Open Data to Strengthen Pathways in Community-Campus Engagement for Community Action on Environmental Sustainability
}

\author{
Leigha McCarroll, Eileen O'Connor, Jason Garlough
}

\begin{abstract}
The goal of this field report is to share learnings on productive dialogue between, and among, communities and campuses. Specifically, we will reflect on practical applications of co-creating a brokering tool to strengthen connections between local environmental non-profit organizations and the six postsecondary institutions in the National Capital Region (Ottawa/Gatineau). The report outlines a process of standardizing and visually depicting data on university and college engagement opportunities, created with an aim of making it easier for potential community partners, students, faculty, and even the general public to search, filter, and discover new programs, researchers, and services that match their interests.
\end{abstract}

KEYWorDs brokering tool; open data; environmental sustainability

The National Capital Region is comprised of Ottawa and Gatineau, neighbouring cities and communities along the Ontario/Quebec border. This bilingual, multicultural region supports the growth of rich community-campus engagement (CCE) opportunities. For the environmental sustainability sector in particular, many professors, researchers, communitybased organizations, and students demonstrate interest in working together for solutions to community-identified needs. While collaboration among these diverse actors is occurring, there are barriers that hinder the creation of more sustainable and purposeful partnerships. While there are a wide variety of CCE opportunities available, it is often difficult for communitybased organizations to navigate the multiple systems postsecondary institutions use to advertise opportunities. This field report will discuss the process of co-creating a communitybased project to inventory the breadth of CCE opportunities at the six local postsecondary institutions. Our goal is to respond to community-identified needs to break barriers around missed opportunities in community-campus engagement, gaps in communication, and setting realistic expectations. We will explore ways to standardize, organize, and sort the information using feedback from the community partners; leveraging existing frameworks, tools, and open data standards. In sum, this paper will share learnings and insight from a local brokering project to develop an open data inventory, made publicly available to other sectors to support ongoing co-creation of knowledge and engagement. 


\section{The Issue}

While there have been numerous examples of successful CCE partnerships in the National Capital Region, this project emerged as a response to observations from various stakeholders that some form of brokerage could facilitate new partnerships in the environmental sustainability sector. During the 2017-2018 academic year, our Ottawa Brokering Group, within the CFICE project, undertook a needs assessment of potential stakeholders. Efforts were made to speak to representatives from all postsecondary institutions located in the National Capital Region and a range of community-based organizations to identify key challenges faced by each stakeholder and collect their feedback on how to respond to the need to create more effective pathways of communication and connection.

Participants in the needs assessment pointed to the various factors in effective CCE: reciprocity, enthusiasm, and communication. Strong communication is arguably the most important factor; however, many participants identified multiple barriers to establishing lines of communication. In colleges and universities, many faculty are part time or on contract with often competing responsibilities. Similarly, many staff of community-based organizations are overworked and have limited capacity to take on the first hurdle of initiating communication about CCE opportunities with local colleges and universities. Determining who to contact, either from a complex institutional directory or searching for the most relevant communitybased organization, can be a stumbling block to initiating partnerships. Sometimes emails or phone calls go unanswered, which can be highly discouraging in pursuing an opportunity. Furthermore, once a partnership is agreed upon, the crucial process of maintaining open and consistent communication to manage expectations and operations is often time-consuming for both parties.

Many respondents also indicated that the complexity and multiple programs at most postsecondary institutions is a major barrier to communication. One participant gave the example of a local community-based organization operating shelters and residences for the homeless in Ottawa. This organization may be receiving calls about opportunities for culinary students, business students, and social work students from one college alone on any given day. Another participant noted that postsecondary institutions seem generally segregated, with insufficient communication between or among departments. For community-based organizations, this may require fielding multiple calls from the same institution, a timeconsuming and often frustrating process.

In addition to challenges with communication, participants in the needs assessment identified several other barriers to building successful CCE relationships. These include staff turnover, scoping, and accountability. The complexity of administration within postsecondary institutions leads many organizations to seek out informal, personal relationships with individuals to streamline communications. Unfortunately, this preference may be problematic when it comes to staff turnover. Without concrete agreements, partnerships will disintegrate when one party moves on to a new position or leaves the organization. When this happens, it can be very difficult for others to pick up the pieces and continue the work if no records remain. 
Second, scoping CCE initiatives was another challenge identified by participants. Students have diverse capacities, and their work ethic and motivation can vary considerably. As one participant noted, the nature of the placement influences how a student comes to be placed with an organization. Their level of commitment and motivation will likely be different if they seek out the placement, as opposed to fulfilling a requirement for a course. It is up to the community-based organization and the postsecondary institution to define what can be done given the time and resources, and this is far from an exact science. This scoping process is a major undertaking, but it is essential for a successful partnership. Without due consideration for the resources available to the community-based organization, and the students in the case of placements, projects can often be far too ambitious. Similarly, for organizations that work with college and university researchers, funding timelines can be an obstacle. Funding to support student placements was also a notable concern, since a great deal of additional human resources is often required for supervision throughout the course of the project.

Third, the resources required to manage and keep students accountable can be an obstacle. Students may require regular check-ups to ensure they are on track, and for an organization with limited staff this can be a considerable drain on their time and energy. Unfortunately, if there are no effective monitoring processes in place, the results of the CCE initiative may not be what the community-based organization expected.

In addition to these challenges, participants observed a major lack of communication and collaboration between institutions in the realm of CCE. Competing priorities and varying student profiles and programs are key reasons for the lack of communication, and some participants noted that meetings around joint degree programs are often the only opportunity for faculty from different institutions to meet and collaborate. Besides these partnerships, postsecondary institutions mostly interact through national or regional networks. These include the Canadian College and University Environmental Network (CCUEN) and, up until recently, the Canadian Alliance for Community Service Learning (CACSL). All the college and university participants agreed there was more to be done to promote collaboration between postsecondary institutions in the National Capital Region. One participant noted that it is useful simply knowing that there are people at different institutions working on similar initiatives. Beyond this, collaboration between postsecondary institutions holds very real implications for CCE, from streamlining communication to developing new and innovative partnerships among multiple stakeholders.

Most participants agreed that there was no definitive example of a brokering organization in the National Capital Region's environmental sector that could bring together colleges, universities, and community-based organizations. For the organizations that do play a brokering role, limited staff and resources means they are unable to meet all the needs of a CCE broker in Ottawa. In relation to this, support in scoping and framing engagement opportunities is a significant gap. Many organizations without experience in CCE may not know the capacity and constraints of students, while from an institutional perspective, there may be an inadequate understanding of the resources available to community-based organizations.

Upon completion of the community needs assessment, we presented the findings back to 
the community and co-developed a plan of action, as described in the following section.

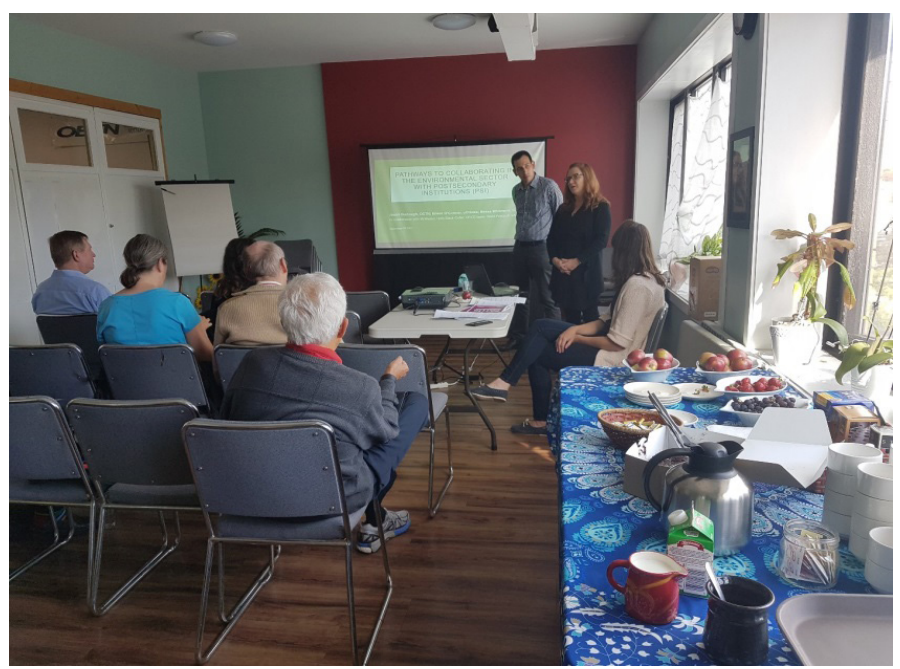

Figure 1. Jason Garlough, Eileen O'Connor, and Julie Johnson from the CFICE team, discussing the community needs assessment with local community-based organizations. Photo credit: Kathryn Norman, Sustainable Eastern Ontario

\section{The Solution}

When it comes to the creation of a brokering tool, community organizations and postsecondary institutions expressed the need to incorporate various components to ensure that the tool would support creating partnerships, not add an additional administrative layer. The table below outlines the challenges expressed by community partners around CCE, and offers solutions presented by the development of a brokering tool.

Table 1. CCE Challenges and Brokering Solutions

\begin{tabular}{|l|l|}
\hline Challenges & Brokering Solutions \\
\hline Lack of time & $\begin{array}{l}\text { This brokering tool consolidates all relevant information } \\
\text { related to each opportunity, eliminating the step of } \\
\text { organizations taking time to conduct further research into the } \\
\text { details of CCE opportunities. }\end{array}$ \\
\hline Lack of resources & $\begin{array}{l}\text { Where applicable, this tool provides detailed information } \\
\text { about the financial commitment required by the community } \\
\text { partner, also listing opportunities that do not require financial } \\
\text { commitment so organizations are fully aware of options. }\end{array}$ \\
\hline $\begin{array}{l}\text { Confusion around appropriate } \\
\text { contact }\end{array}$ & $\begin{array}{l}\text { This tool lists the most appropriate contact person(s) for the } \\
\text { CCE opportunity. }\end{array}$ \\
\hline
\end{tabular}

Engaged Scholar Journal: Community-Engaged Research, Teaching, and Learning 


\begin{tabular}{|l|l|}
\hline $\begin{array}{l}\text { College and University websites } \\
\text { too difficult to navigate }\end{array}$ & $\begin{array}{l}\text { The tool consolidates all relevant information from college } \\
\text { and university websites, eliminating the need to navigate these } \\
\text { to find information. }\end{array}$ \\
\hline Lack of response from contacts & $\begin{array}{l}\text { The tool lists alternate contacts where applicable in case of } \\
\text { lack of response from the lead contact. }\end{array}$ \\
\hline $\begin{array}{l}\text { Wide variety of procedures, } \\
\text { guidelines, institutional } \\
\text { programming }\end{array}$ & $\begin{array}{l}\text { The tool provides a one-stop-shop for CCE opportunities } \\
\text { and lists all relevant procedural details for each opportunity. }\end{array}$ \\
\hline Lack of clear theme/direction & $\begin{array}{l}\text { The tool's specific thematic focus on the environmental } \\
\text { sector will make for a highly relevant and well-defined tool } \\
\text { for community partners in this sector. }\end{array}$ \\
\hline
\end{tabular}

The guiding objective of this brokering project is to respond to community-identified needs to break barriers around missed opportunities in community-campus engagement, gaps in communication, and setting realistic expectations. As such, members of the CFICE Brokering Working Group endeavoured to create a brokering tool: the Opportunities Database. In creating the Database, standardizing the data was a major priority. As the Database incorporates Open Data and is public and free to use, standardizing data structures was critical for maximizing the use of the information related to CCE opportunities.

\section{The Process}

In order to build a robust Opportunities Database, the first step was to establish the data structures and fields that would guide which information to collect. In the needs assessment, organizations reported that they required specific information on various fields such as the type and nature of the CCE opportunity, the academic level of the student, the number of student hours required, the amount of postsecondary resources required (both human and financial), timelines and deadlines, and contact information. For each of these categories, we established standards in order to provide the fullest picture of the opportunity, while also standardizing the type of information collected across all postsecondary institutions. For example, for the field "Type of CCE," we relied on the Work-Integrated Learning typology conceptualized by the Higher Education Quality Council of Ontario to classify the opportunities as Systematic Training, Structured Work Experience, or Institutional Partnerships.

Once the data standards were established, we began to meet with community partners, professors, and staff at postsecondary institutions to identify various types of opportunities for CCE. These meetings allowed us to build personal connections with partners while raising awareness of the tool and receiving useful information on CCE opportunities at each local college and university. An example of this is a meeting that took place in June 2018 with Simon Tremblay-Pepin, assistant professor and director of the Élisabeth-Bruyère School of Social Innovation at the University of St. Paul. During this meeting, the CFICE team discovered a promising opportunity for CCE in Ottawa, as Dr. Tremblay-Pepin briefed us on the upcoming launch of an Honours Bachelor of Arts in Social Innovation, in addition to the 
school's existing certificate in Social Innovation and Graduate Diploma in Social Organization Development. As of Fall 2018, the School will be offering the programs, which aim to offer theoretical and practical training in collective action and social innovation, are grounded in a local context, with various courses offering practicum opportunities in the Ottawa community. This meeting reinforced the importance of connecting with postsecondary institutions to ask them about upcoming initiatives related to CCE.

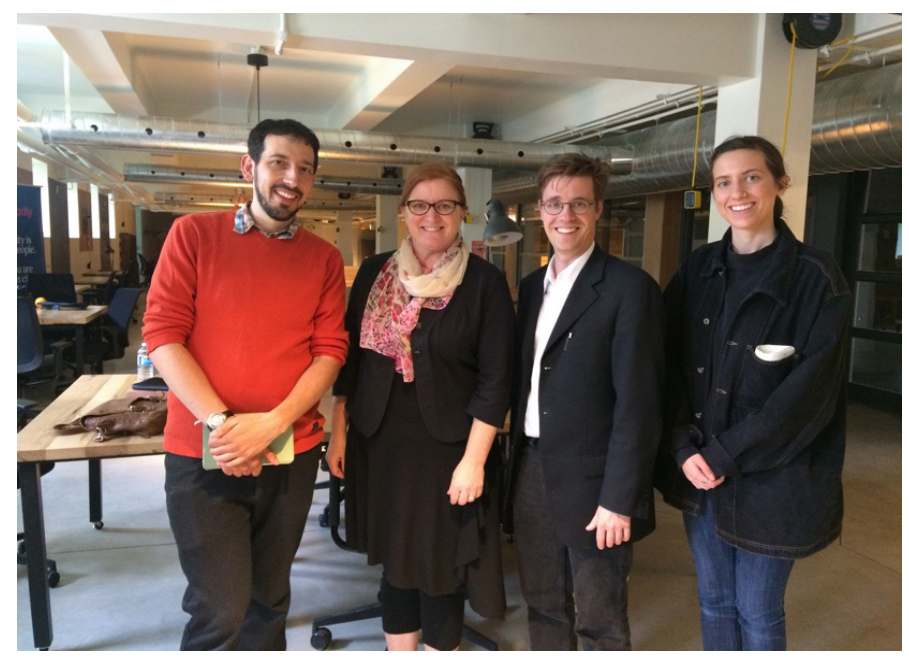

Figure 2. The CFICE Team visiting the Mauril-Bélanger Social Innovation Workshop at St. Paul University (Ottawa), June 2018

In terms of logistics, we used a publicly-accessible Google Sheet to build a database to showcase these opportunities offered by postsecondary institutions in the National Capital Region in the environmental and sustainability sector. We also combed institutional websites for additional information on available opportunities and timelines. For users, we created a Kumu visualization that links to the Google Sheet, making the information visually-appealing, easy to navigate, and downloadable. This allows the community to filter, sort, and publish the thousands of community-campus engagement opportunities available in their region in any format they prefer or find useful. We also created a User Guide with step-by-step instructions and a glossary to help users as they navigate the Opportunities Database. Figure 3 depicts a snapshot from Kumu of the CCE opportunities we gathered for the University of Ottawa. 


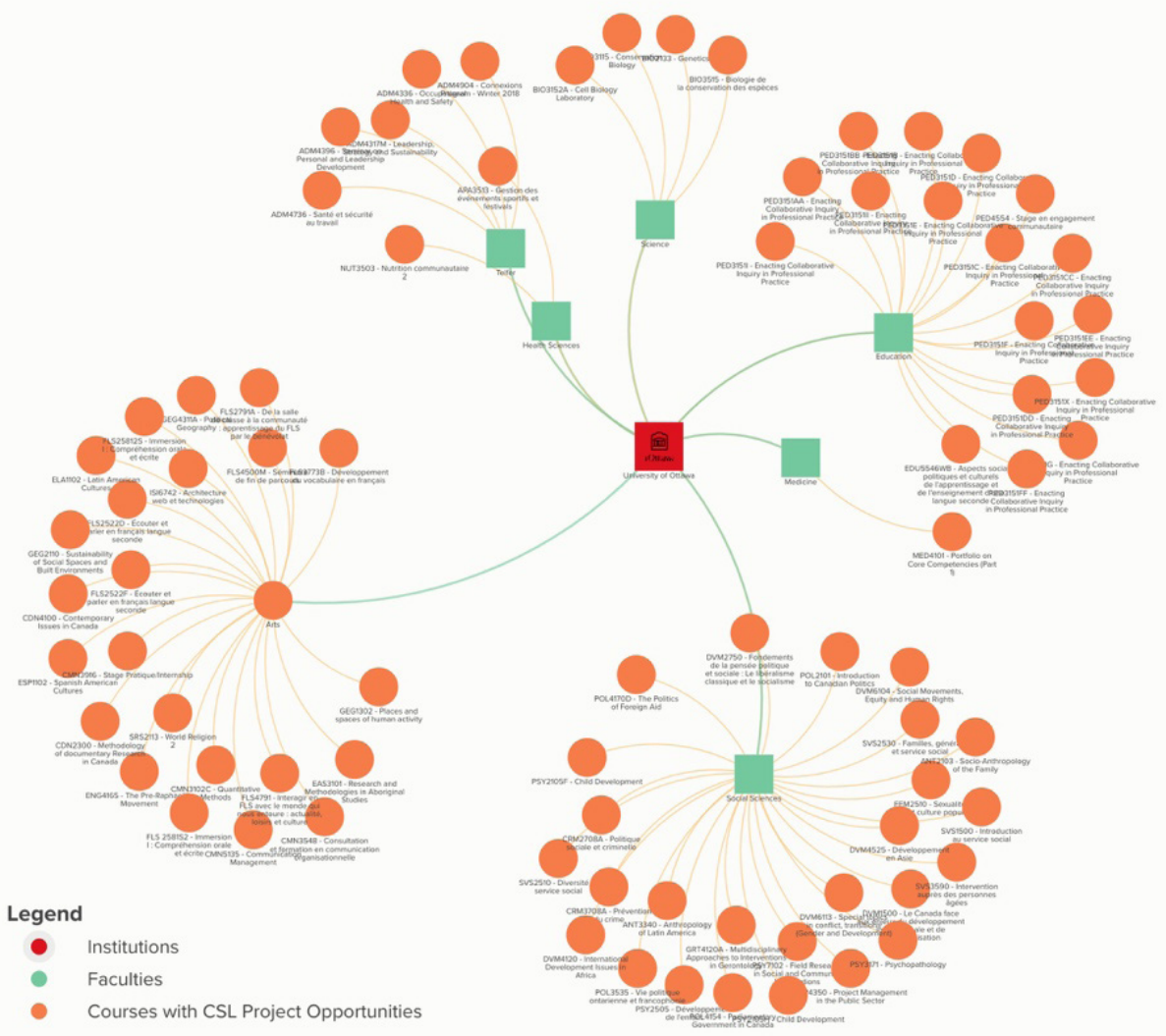

Figure 3. Kumu Visualization Snapshot: CCE at the University of Ottawa

\section{Next Steps}

Now that we have amassed a significant amount of information on CCE opportunities in the Ottawa environmental sustainability sector, we continue to refine the data standards and categories to ensure the Opportunities Database is as user-friendly as possible. Members of the project team recently attended an Ottawa Civic Tech meetup, where we had an opportunity to share our project and data structure with volunteers for feedback and advice on best practices in Open Data.

We will host a meeting with community partners in Fall 2018 to present the Opportunities Database and invite community partners to test it out as a pilot. We will incorporate feedback from this meeting to further improve the tool. In the coming months, we will launch the Opportunities Database publicly via CFICE's networks and channels.

In summary, this project is an enriching undertaking, that needs consistent and meaningful interactions with the various stakeholders to ensure it corresponds to community and postsecondary institution needs to the greatest extent possible. It demonstrates the importance of co-creation and of data standardization as a means to reduce barriers and pave the way for 
lasting connections between community-based organizations and postsecondary institutions.

\section{Acknowledgments}

This research was supported by the Social Sciences and Humanities Research Council of Canada (SSHRC) through the Community First: Impacts of Community Engagement Project (CFICE). We would also like to acknowledge the work, guidance, and invaluable input from talented research assistants, Colton Brydges and Leigha Mccarroll, as well as contributions from colleagues Elizabeth Whitmore, Peter Andree, Julie Johnson, and community members from various Ottawa-area environmental non-profit organizations.

\section{About the Authors}

Jason Garlough is the Executive Director of Ottawa Eco-Talent Network (OETN).

Leigha McCarroll is a PhD candidate in Public Policy at Carleton University.

Eileen O'Connor (corresponding author) is an Associate Professor in the School of Human Kinetics at the University of Ottawa. Email: eoconnor@uottawa.ca

The authors are members of the Ottawa Brokering Working Group of the Community First: Impacts of Community Engagement (CFICE) project, a seven-year Social Sciences and Humanities Research Council of Canada-funded action research project. 